\title{
Evaluation of Antioxidant Activity and Cytotoxic Property of Methanolic Extract of Flemingia macrophylla (Willd.)
}

\author{
Anjuman Ara Begum, Md. Mosiul Haque, Mahfuzul Islam and Sukalyan Kumar Kundu
}

Department of Pharmacy, Jahangirnagar University, Savar, Dhaka-1342, Bangladesh

\begin{abstract}
Flemingia macrophylla locally known as 'Charchara' in Bangladesh is a medicinal herb. Being a member of the Fabaceae family it claims a number of medicinal uses including hypoglycemic activity, neuroprotective effect and gynecological remedies. Methanolic extract of F. macrophylla was investigated to evaluate its antioxidant and general toxic properties in this study. Antioxidant potential was evaluated using total antioxidant capacity, total phenol contents, total flavonoid contents and DPPH (1,1-diphenyl-2-picrylhydrazyl) assays. Both leaf and stem extracts of F. macrophylla were found to possess significant amount of phenolics and flavonoids, expressed as gallic acid equivalents (GAE) and quercetin equivalent (QE), respectively. Interestingly total phenol content was equal for both leaf and stem extract and it was $43.8 \mathrm{mg} \mathrm{GAE} / \mathrm{g}$. Total flavonoid content was found to be 64.4 and $39.1 \mathrm{mg} \mathrm{QE} / \mathrm{g}$ for leaf and stem extract, respectively. The total antioxidant capacity was expressed as ascorbic acid equivalents (AAE) and for leaf it was $5.067 \mathrm{mg} / \mathrm{gm} \mathrm{AAE}$ and for stem $0.8167 \mathrm{mg} / \mathrm{gm}$ AAE. DPPH scavenging activity was determined by comparing with ascorbic acid. The $\mathrm{IC}_{50}$ values were $19.95,125.89$ and $707.94 \mu \mathrm{g} / \mathrm{ml}$ for ascorbic acid, leaf and stem extract, respectively. The results of the present study on methanolic extracts of $F$. macrophylla revealed the presence of moderate antioxidant activity and extract of leaves produced better results than stem of the plant. In brine shrimp lethality bioassay, methanolic extract of $F$. macrophylla exhibited insignificant cytotoxicity.
\end{abstract}

Key words: Flemingia macrophylla, Antioxidant, DPPH Scavenging activity, Cytotoxicity.

\section{Introduction}

Plants have been the basis of many traditional medicines throughout the world for thousands of years and continue to provide new remedies (Samuelsson, 2004). Many drugs used in contemporary medicine have been derived from plants and were originally discovered through the traditional use by the indigenous people. This study is based on ethnobotanical knowledge of the plant Flemingia macrophylla. It is a woody, deep-rooting, tussock-forming shrub, 1-4 m tall. Different parts of Flemingia species have been reported useful traditionally for treating different kinds of diseases, like roots for rheumatism, arthropathy, melangia, chronic nephritis, etc. (Lie et al., 2008); stems in rheumatism, inflammation, etc. (Hsieh et al., 2010). F. macrophylla has also been found to possess hepatoprotective and neuroprotective activities (Hsieh et al., 2011; Young et al., 2005).
Antioxidants from the natural source are very much promising in the present natural product studies due to their better efficacy with less adverse effects. Antioxidants protects cell damage significantly scavenging the free radicals and reactive oxygen species developed in various diseased conditions like cancer, hepatic failure, diabetes mellitus, arteriosclerosis, inflammation, renal failure, atherosclerosis, neurodegenerative disorders, etc. (Bulkley, 1983; Dormandy, 1983; Niki, 1995; Frei, 1999). Therefore, in our present study, it was aimed to investigate and compare the antioxidant activity of methanolic extracts of leaf and stem of F. macrophylla. Moreover, for screening of general toxicity and cytotoxic properties, the brine shrimp lethality assay was also conducted.

Correspondence to: Anjuman Ara Begum, E-mail: anjumantanya@yahoo.com 


\section{Materials and Methods}

Plant material: Flemingia macrophylla was collected from Chandra, Gazipur and the botanical identity was authenticated by the taxonomist of the National Herbarium of Bangladesh, Mirpur, Dhaka. The voucher specimens (DACB-35624) of the plant have been deposited in the herbarium for future reference.

Drugs and chemicals: 1,1-diphenyl-2-picryl-hydrazyl (DPPH), ascorbic acid, quercetin and gallic acid were obtained from Sigma Chemical Co (MO, USA). Folinciocalteu reagent (FCR) and Griess reagent were purchased from Merck, Germany. All other chemicals and reagents were of analytical grade.

Extraction: The leaves and stems of the plant were collected in fresh condition. They were sun-dried first and then dried in an oven at reduced temperature $\left(<50^{\circ} \mathrm{C}\right)$ to facilitate grinding. $350 \mathrm{gm}$ powdered materials for each part were submerged separately in $1500 \mathrm{ml}$ methanol into two air-tight flat bottomed containers for seven days, with occasional shaking and stirring. The extracts were then filtered and dried on an electrical water bath at $50{ }^{\circ} \mathrm{C}$.

Phytochemical screening of crude plant extract: In phytochemical screening the methanolic extracts were qualitatively checked for various components using the following reagents and chemicals - Dragendorff's reagent for alkaloids, $\mathrm{Mg}$ and $\mathrm{HCl}$ for flavonoids, Ferric chloride and Potassium dichromate solutions for tannins, Libermann-Burchard reagent for saponins and Molisch's test for carbohydrates and general test for glucosides. Components were identified by observing the Characteristic color changes (Trease and Evans, 1983).

Determination of total phenols: Total phenols were determined by Folin-Ciocalteu reagent (Folin and Ciocalteu, 1927). $1.0 \mathrm{ml}$ of each plant extract $(10 \mu \mathrm{g} / \mu \mathrm{l})$ or standard of different concentrations $(250,200,150,100$ and $50 \mu \mathrm{g} / \mathrm{ml}$ ) were taken in different test tubes. $5 \mathrm{ml}$ of Folin-Ciocalteu (diluted 10 fold) and $4 \mathrm{ml}$ of Sodium carbonate reagent was added to the test tubes. The test tubes were incubated for 30 minutes at $20^{\circ} \mathrm{C}$ to complete the reaction. The absorbance of the solutions was measured at $765 \mathrm{~nm}$ using a UV-Vis spectrophotometer against distilled water as blank. Total phenolic compounds in plant extracts were expressed in terms of gallic acid equivalent ( $\mathrm{mg} / \mathrm{g}$ of dry mass), which is a common reference compound. The result was calculated from the regression equation of the calibration curve $(\mathrm{y}=0.009 \mathrm{x}+$ $\left.0.058 ; \mathrm{R}^{2}=0.997\right)$.

Determination of flavonoid content: Aluminum chloride colorimetric method was used for flavonoids determination (Chang et al., 2002). $1 \mathrm{ml}$ of sample was mixed with $3 \mathrm{ml}$ of methanol, $0.2 \mathrm{ml}$ of $10 \%$ aluminum chloride, $0.2 \mathrm{ml}$ of $1 \mathrm{M}$ potassium acetate and $5.6 \mathrm{ml}$ of distilled water. It was kept at room temperature for 30 minutes. The absorbance of the reaction mixture was measured at $415 \mathrm{~nm}$. The calibration curve was prepared by preparing quercetin solution at concentrations 12.5 to $100 \mu \mathrm{g} / \mathrm{ml}$ in methanol.

Determination of total antioxidant capacity: The assay is based on the reduction of Mo (VI) to Mo (V) by the extract and subsequent formation of a green phosphate/Mo (V) complex at acidic pH (Prieto et al., 1999). The antioxidant capacity was expressed as ascorbic acid equivalent (AAE). The plant extract $(0.3 \mathrm{ml})$ was combined with $3 \mathrm{ml}$ of reagent solution ( $0.6 \mathrm{M}$ sulphuric acid, $28 \mathrm{mM}$ sodium phosphate and $4 \mathrm{mM}$ ammonium molybdate). The mixture was incubated at $95^{\circ} \mathrm{C}$ for 90 minutes. After the mixture had cooled to room temperature, the absorbance of the solution was measured at $695 \mathrm{~nm}$ against an appropriate blank. Total antioxidant capacity of extract was measured from the calibration curve constructed by using ascorbic acid standard solutions.

$D P P H$ scavenging activity: DPPH free radical scavenging activity of the extracts was measured by the method developed by Manzorro et al. (1998). $0.2 \mathrm{ml}$ of sample (extract or standard) of each concentration (500, $200,100,50,10,5 \mu \mathrm{g} / \mathrm{ml}$ ) were mixed with $2 \mathrm{ml}$ of DPPH solution $(0.5 \mathrm{mM})$. After 30 minutes of reaction at room temperature in dark place, the absorbance was measured at $517 \mathrm{~nm} . \mathrm{IC}_{50}$ values (concentration of samples required to scavenge $50 \%$ of free radicals) were calculated from the regression equation, developed by plotting concentration of samples versus percentage inhibition of free radicals. Ascorbic acid was used as positive control.

Brine shrimp lethality bioassay: This technique was applied for determination of general toxic property of the plant extract (Meyer et al., 1982 and McLaughlin et al., 1998). Test samples of different concentrations (500 $\mu \mathrm{g} / \mathrm{ml}$ to $1 \mu \mathrm{g} / \mathrm{ml}$ ) were prepared in dimethylsulfoxide (DMSO). Ten brine shrimp nauplii were taken in vials 
containing $5 \mathrm{ml}$ of simulated sea water. Then samples were added to pre-marked vials with micropipette. After 24 hours and the vials were inspected using a magnifying glass and the number of survived nauplii in each vial was counted. From this data, the percent (\%) of lethality of the brine shrimp nauplii was calculated for each concentration. Vincristine sulphate was used as positive control in this study.

\section{Results and Discussion}

Since the chemical constituents present in a plant are directly responsible for its therapeutic and other pharmacological properties, the constituents of the plant which are detected during this investigation should have some direct relationship with local medicinal uses. The results of various qualitative chemical tests for the detection of chemical constituents of F. macrophylla are shown in the Table 1.

Table 1. Results of phytochemical screening of methanol extract of different parts of $F$. macrophylla

\begin{tabular}{lccccccc}
\hline $\begin{array}{l}\text { Plant } \\
\text { parts }\end{array}$ & Carbohydrate & Glycosides & Glucosides & $\begin{array}{c}\text { Anthraquinone } \\
\text { glycoside }\end{array}$ & Alkaloids & Saponins & Flavonoids Steroids Tannins \\
\hline $\begin{array}{l}\text { Stem } \\
\text { and }\end{array}$ & + & + & - & + & \pm & - & + \\
Leaf & & & & & & + & + \\
\hline
\end{tabular}

'+’ Indicates Positive Reaction, '-’ Indicates No Reaction, ‘ \pm ' Indicates Presence or Absence could not be ascertained

Table 2. Antioxidant capacity of different parts of $F$. macrophylla.

\begin{tabular}{lcccc}
\hline \multicolumn{1}{c}{ Sample } & $\begin{array}{c}\text { Total phenol content } \\
(\mathrm{mg} \mathrm{GAE} / \mathrm{g})\end{array}$ & $\begin{array}{c}\text { Total flavonoid content } \\
(\mathrm{mg} \mathrm{QE} / \mathrm{g})\end{array}$ & $\begin{array}{c}\text { DPPH free radical scavenging } \\
\text { activity }\left(\mathrm{IC}_{50} \mu \mathrm{g} / \mathrm{ml}\right)\end{array}$ & $\begin{array}{c}\text { Total antioxidant capacity } \\
(\mathrm{mg} \mathrm{AAE} / \mathrm{g})\end{array}$ \\
\hline Ascorbic Acid & & & $19.95 \pm 0.22$ & $5.067 \pm 0.31$ \\
Leaf & $43.8 \pm 0.22$ & $64.4 \pm 0.56$ & $125.89 \pm 0.45$ & $0.8167 \pm 0.26$ \\
Stem & $43.8 \pm 0.13$ & $39.1 \pm 0.29$ & $707.94 \pm 0.21$ & \\
\hline
\end{tabular}

The content of total phenolics in the methanolic plant extracts was determined using the Folin-Ciocalteu assay. The content of phenolics was found to be $43.8 \mathrm{mg} \mathrm{GAE} / \mathrm{g}$ in each extracts (Table 2). The antioxidant activity of the phenolic compounds is mainly due to their redox properties, which can play an important role in absorbing and neutralizing free readicals, quenching singlet and triplet oxygen, or decomposing peroxides (Osawa, 1994).

Flavonoid content was calculated from the regression equation of the calibration curve $(y=0.005 x-0.005)$ and is expressed as quercetin equivalents $(\mathrm{QE})$. The flavonoid content was determined as $64.4 \mathrm{mg} \mathrm{QE} / \mathrm{g}$ for leaf extract and $39.1 \mathrm{mg} \mathrm{QE} / \mathrm{g}$ for stem extract (Table 2). Flavonoids are polyphenolic compounds that are ubiquitous in nature and are mainly categorized as flavonols, flavones, flavanones, isoflavones, catechins, anthocyanidines and chalcones according to their chemical structures.
The total antioxidant capacities of the methanolic extracts of the selected plant were determined from the calibration curve established by ascorbic acid at $695 \mathrm{~nm}$. The regression line was $y=0.006 x+0.0101$ and $R^{2}=0.991$. The ascorbic acid equivalent (AAE) for leaf and stem extract were 5.067 and $0.8167 \mathrm{mg} / \mathrm{g}$, respectively.

In DPPH scavenging assay, $\mathrm{IC}_{50}$ values of the methanolic extracts of $F$. macrophylla were found to be 125.89 and $707.94 \mu \mathrm{g} / \mathrm{ml}$ for leaf and stem, respectively. $\mathrm{IC}_{50}$ value for ascorbic acid was $19.95 \mu \mathrm{g} / \mathrm{ml}$. Fig 1 shows the amount of extract needed for $50 \%$ inhibition $\left(\mathrm{IC}_{50}\right)$.

Yet now most of the reliable work has been performed for the 'aqueous' extract of F. macrophylla. So this work is a new conjunction for this research. DPPH reading of the plant extract is not very close to the Ascorbic acid. It is because the plant extract is in crude form and it is quite possible to be a potent antioxidant 
after bioactive compound isolation. In similar work with the aqueous extract of $F$. macrophylla, $\mathrm{IC}_{50}$ value was found $113 \mu \mathrm{g} / \mathrm{ml}$ (Syiem et al., 2009) which is close to this study result for the same $\left(\mathrm{IC}_{50}=125 \mu \mathrm{g} / \mathrm{ml}\right.$ for leaf extract). In the same experiment conducted by Syiem et al. (2009), total phenol content was found as 200 and $12.7 \mathrm{mg} \mathrm{GAE} / \mathrm{g}$ for the methanolic and aqueous extract, respectively whereas, in our study, the value for total phenol content was found $43.8 \mathrm{mg} \mathrm{GAE} / \mathrm{g}$ for both of the methanolic extracts of leaf and stem of $F$. macrophylla. The reasons for variation in findings might be due to nature of soil, condition of growth of plants method variation, variation in chemical grade and UV detection error. Total flavonoid content and total antioxidant reading also showed satisfactory result. It is clear from all of the experiments that the 'Leaf' extract has greater antioxidant property than the 'Stem' extract although both of them exhibited moderate antioxidant activity. Moreover, the positive result found for glycoside, anthraquinone glycoside, flavonoid and tannin in phytochemical screening also gave indication for antioxidant property.

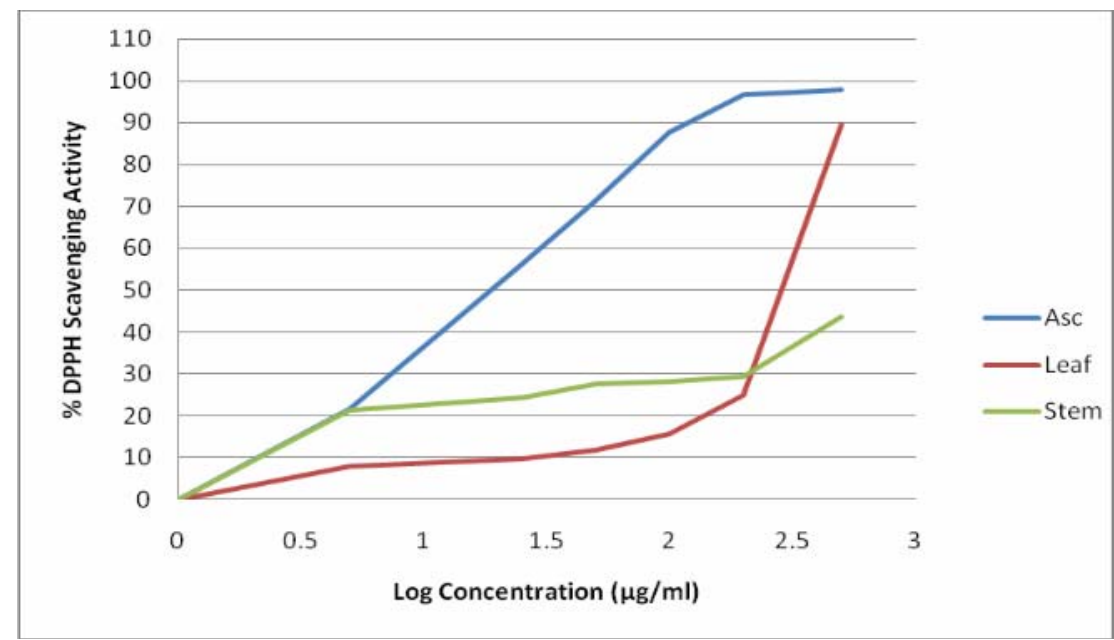

Figure 1. comparative DPPH scavenging activity.

In brine shrimp lethality bioassay, after 24 hours all of the samples showed insignificant lethality. Median lethal concentration or $\mathrm{LC}_{50}$ values were found $174582.2 \mu \mathrm{g} / \mathrm{ml}$ for stem extract and $889.962 \mu \mathrm{g} / \mathrm{ml}$ for leaf extract, whereas the reference standard vincristine sulphate exhibited $\mathrm{LC}_{50}$ values of $0.45 \mu \mathrm{g} / \mathrm{ml}$. It is clearly evident from the above findings that the leaves and stem extracts of F. macrophylla have moderate antioxidant activity but almost no cytotoxic property. Future endeavors to isolate the active principles from this plant can assist to open up exciting new therapeutic avenues by finding fundamental medicinal potentiality.

\section{Acknowledgement}

One of the authors (Anjuman Ara Begum) is indebted to Jahangirnagar University for providing research grant to conduct the study.

\section{References}

Bulkley, G. B. 1983. The role of oxygen free radicals in disease processes. Surgery, 94: 407-411.

Chang, C., Yang, M. and Wen, H. 2002. Estimation of total flavonoid content in ssspropolis by two complementary colorimetric methods. J. Food Drug Anal. 10, 178-182.

Dormandy, T. L. 1983. An approach to free radicals. Lancet. 2, 1010-1014.

Folin, O. and Ciocalteu, V. 1927. On tyrosine and tryptophane determination in proteins. J. Biol. Chem. 27, 627-650.

Frei, B. 1999. On the role of vitamin C and antioxidants in atherogenesis and vascular dysfunction. Proc. Soc. Exp. Biol. Med., 222, 196-204.

Hisch, P-C., Huang, G-J., Ho, Y-L., Lin, Y-H., Huang, S-S., Chiang, Y-C., Tseng M-C., and Chang, Y.S. 2010. Activities of antioxidants, $\alpha$-Glucosidase inhibitors and aldose reductase inhibitors of the aqueous extracts of four Flemingia species in Taiwan. Botanical Studies, 51, 293 302. 
Hsieh, P., Ling, H.Y., Jhong, G., Hsing, M., Shyun, S., Chi, H.W., Shiun, C.Y. 2011. Hepatoprotective effect of the aqueous extract of Flemingia macrophylla on carbon tetrachloride-induced acute hepatotoxicity in rats through anti-oxidative activities. Am. J. Chin. Med. 39, 349-365

Li, H., Yang, M., Miao, J., and Ma, X. 2008. Prenylated isoflavones from Flemingia philippinensis. Magn. Reson. Chem. 46, 1203-1207.

Manzorro, L., Anese, M., and Nicoli, M.C. 1998. Antioxidant properties of tea extracts as affected by processing. Lebensmittel-Wissenschaft Und-Technologie, 31, 694-698.

McLaughlin, J.L., Anderson, J.E. and Rogers, L.L. 1998. The use of biological assays to evaluate botanicals. Drug Infor. J. 32, 513-524.

Meyer, B.N., Ferrigni, N.R., Putnam, J.E., Jacobsen, J.B., Nicholsand, D.E. and Mclaughlin, J.L.1982. Brine shrimp; a convenient general bioassay for active plant constituents. Planta Med. 45, 31-34.

Niki, E. 1995. Antioxidants, free radicals and biological defense. In: Niki, E., shimasaki, H., \& Mino, M. (Eds.), Japan Scientific Societies Press, Tokyo, p. 3.
Osawa, T. 1994. Novel Natural Antioxidants for utilization in food and biological systems, Posthavest biochemistry of Plant food-materials in the tropics, Tokyo, Japan: Japan Scientific Press. 1, pp. 241-251.

Prieto, P., Pineda, M., and Aguilar, M. 1999. Spectrophotometric quantitation of antioxidant capacity through the formation of a phosphomolybdenum complex: Specific application to the determination of vitamin E. Anal. Biochem. 269, $337-$ 341.

Samuelsson, G.2004. Drugs of Natural Origin: A Text of Pharmacognosy. $4^{\text {th }}$ revised ed. Swedish Pharmaceutical Press, Stockholm, Sweden. pp. 417-429.

Syiem, D., Sharma, R., Saio, V. 2009. In vitro study of the antioxidant potential of some traditionally used medicinal plants of north-east India and assessment of their total phenolic Content. Pharmacologyonlin. 3, 952-965.

Trease, G.E. and Evans, W.C. 1983. Pharmacognosy. $12^{\text {th }}$ ed. London, Baillieere Tindal.

Young J.S., Chuen, N.W., Wan, Y.W., Yun, L.L. 2005. Neuroprotective flavonoids from Flemingia macrophylla. Planta Med. 71, 835-840. 